\title{
Modeling Freight Truck Trips in Birmingham Using Tour-Based Approach
}

\author{
Ehsan Doustmohammadi, Virginia P. Sisiopiku, Andrew Sullivan
}

Department of Civil, Construction, and Environmental Engineering, University of Alabama at Birmingham, Birmingham, AL, USA

Email: ehsan12@uab.edu

How to cite this paper: Doustmohammadi, E., Sisiopiku, V.P. and Sullivan, A. (2016) Modeling Freight Truck Trips in Birmingham Using Tour-Based Approach. Journal of Transportation Technologies, 6, 436-448. http://dx.doi.org/10.4236/jtts.2016.65035

Received: September 10, 2016

Accepted: October 17, 2016

Published: October 20, 2016

Copyright $\odot 2016$ by authors and Scientific Research Publishing Inc. This work is licensed under the Creative Commons Attribution International License (CC BY 4.0).

http://creativecommons.org/licenses/by/4.0/ (c) (i) Open Access

\begin{abstract}
This research study explores the use of an innovative freight tour-based approach to model truck trips as an alternative to the conventional trip-based approach. The tour-based approach is more realistic as it captures the intermediate stops of each truck and reflects the implications of those stops on vehicle miles traveled (VMT). The paper describes the truck tour-based model concept, and presents the framework of a truck tour-based travel demand forecasting approach. As a case study, Global Positioning System (GPS) truck data are used to determine origin, destination, and truck stops for trucks moving within the Birmingham, Alabama region. Such information is then utilized to model truck movements within the study region as individual truck tours. The tour-based model is ran, and the resulting performance measures are contrasted to those obtained from the conventional trip-based planning model used by the Regional Planning Commission of Greater Birmingham (RPCGB). This case study demonstrates the feasibility of using a tour-based freight demand forecasting model as an alternative to the conventional 4-step process currently used to estimate truck trips in the Birmingham region. The results and lessons learned from the Birmingham case study are expected to improve truck movement modeling practices in the region and advance the accuracy of truck travel demand forecasting models at other locations in the future.
\end{abstract}

\section{Keywords}

Conventional Freight Demand Forecasting Models, Tour-Based Model, Truck GPS Data

\section{Introduction}

Truck transportation plays an important role in serving freight transportation needs and supporting the economy while also contributing to urban congestion and pollution. 
Thus the US Department of Transportation (USDOT), State Departments of Transportation (DOTs), and many regional Metropolitan Planning Organizations (MPOs) have a kin interest in modeling truck movements in great detail and accurately predicting future truck travel demand patterns. However, comprehensive modeling of truck trips is still limited due to the complexity of freight movements and the lack of availability of detailed truck trip data [1]-[9].

Conventional travel demand forecasting models use the aggregate four-step methodology to estimate truck trips. Traditionally, such models do not model truck trips separately, but rather include them implicitly in the non-home-based (NHB) trip category. Moreover, conventional trip-based models measure travel in terms of independent trips between pairs of zones and are unable to capture trip chaining behavior which is often prevalent in truck trips.

For years, one of the reasons behind the lack of detailed modeling of truck trips in conventional travel demand forecasting models was the difficulty of obtaining detailed data. Recently, the proliferation of global positioning systems (GPS) created new opportunities for data collection and analysis, which, in turn, allowed for improvements in modeling practices. Availability of GPS-based truck travel data allows users to obtain detailed disaggregated truck travel data so that regional planning organizations can now develop freight-demand models in conjunction with travel demand models more. In combination with other existing data sources, GPS data provide detailed origindestination (O-D) information, critical routes for goods movement, operating speed of a large sample of trucks along major highways, travel times, and sample flows for intercity truck traffic along truck corridors that can improve the accuracy of modeling truck movements [10]-[14].

Despite the advantages of GPS data, such data must be used with caution because they represent an unknown sample of the universe of truck trips. Moreover, data confidentiality requirements prevent information about vehicle type and ownership from being shared.

This study showcases the use of GPS-based truck travel data to forecast truck trips in the Birmingham, AL region using the tour-based freight modeling approach as an alternative to the conventional trip-based demand forecasting process currently employed. The tour-based model uses a disaggregate approach to capture the intermediate stops of each truck and to reflect the implications of those stops on vehicle miles traveled (VMT).

In this study, four months of GPS-based truck movement data are utilized to obtain origin, destination, and stop locations information for trucks moving within the Birmingham region. Such information is then used to model truck movements within the study region as individual truck tours. The traditional trip-based planning model employed by the Regional Planning Commission of Greater Birmingham (RPCGB) and the new tour-based truck model of the Birmingham region are run and trip estimates are obtained for the year 2040 and compared.

This paper offers a brief introduction of the tour-based modeling concept and a de- 
scription of the Birmingham case study. More specifically, the paper first presents the conventional trip-based Birmingham planning model and the initial efforts to develop a tour-based Birmingham truck model. Then, it summarizes updates to the tour-based Birmingham truck model and discusses validation efforts. Next, comparisons are performed between performance measures obtained from the conventional Birmingham trip-based and the new tour-based models to identify similarities and differences in estimates from the two modeling approaches. Finally, the paper summarizes the main study conclusions and offers recommendations for future research.

\section{Tour-Based Model Background}

Over the past half-century, the conventional aggregate four-step methodology has been used to estimate truck trips. Conventional trip-based models measure travel in terms of independent trips between pairs of zones [7] [8] [15]. This approach ignores the relationship between trips that may be segments of a tour. Such trips account for an estimated $20 \%$ of all private automobile trips. In recent years, activity-based or tour-based models have been introduced to address this issue [16]. In these new models, traffic analysis zones are still used to describe and organize demographic data and the transportation system, but travel is described in terms of tours. Some of these tours have intermediate stops for various purposes, an approach that is more representative of the way in which people actually travel. Typically, these new models require new homeinterview surveys and lengthy and expensive calibration efforts. Because a standard framework for such models does not yet exist, those that have been developed have been highly customized and demanded great development effort [9] [17]-[21].

For truck trips, multi-stop tours comprise an even higher share of total truck travel as compared to private automobile trips. While some long-haul truck tours are single stop tours (i.e., pick up freight at one location and drop it at another), many trucks make multiple stops as they travel from their origin to their destination that are not accounted for in the conventional travel demand forecasting framework. Some of these missed truck trips are short trips to deliver goods within urban areas [14] [22]-[26]. As with the private automobile travel, the tour-based approach appears well suited to modeling truck travel in order to better capture the actual trip making patterns of truck trips. Also, truck travel is considerably more diverse in nature than personal travel, which makes it suited to a disaggregate approach. Until lately, however, there have been only limited efforts to develop tour-based truck models. This has likely been due to the difficulty in obtaining the detailed truck movement data necessary to develop the truck tours. However, the relatively recent availability of GPS truck data has allowed planning organizations to begin to tackle this challenge and some tour-based truck models emerged, most notably in Phoenix, AZ and Brunswick, GA [1] [14].

\section{Birmingham Trip-Based Model}

The Regional Planning Commission of Greater Birmingham (RPCGB) maintains the regional travel demand forecasting model for Jefferson and Shelby counties in the Bir- 
mingham area (see Figure 1). RPCGB is responsible for 6 counties, but the travel demand model only covers the Birmingham Metropolitan Planning Area, which is the census-defined urbanized area plus areas that will likely become urbanized within the next 20 years.

Currently, RPCGB uses a conventional trip-based model which does not explicitly include a freight model, but rather generates truck trips by applying a standard factor to overall vehicle trip productions.

An initial effort to introduce a tour-based truck model was made that resulted into a pilot Birmingham tour-based model. However, significant changes in the number of traffic analysis zones (TAZ's) used in the current RPCGB model makes the prototype model practically unusable. To address this issue, this study used the RPCGB year 2040 model and modified it to incorporate the tour-based truck model in an effort to demonstrate its feasibility and ultimately improve the accuracy of freight travel demand forecasting model. The following paragraphs summarize the model framework, data used, initial model development process and recent updates.

\section{Birmingham Tour-Based Truck Model Development}

The Birmingham tour-based truck model's framework applied in this study is based on the work of Kuppam et al. which described a tour-based truck model developed for the Phoenix area based on truck GPS data [14]. That model includes components for tour

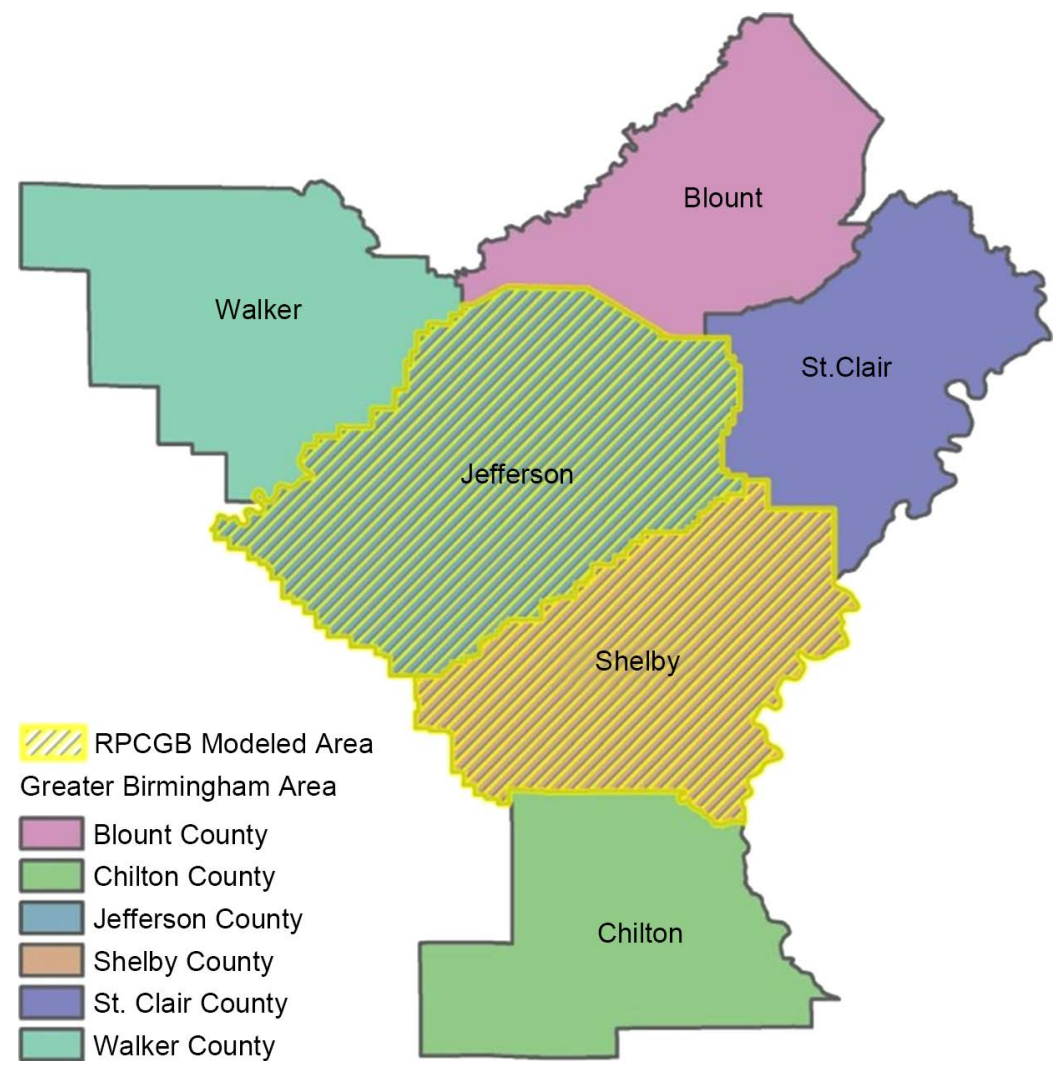

Figure 1. RPCGB modeled area. 
generation, stop generation, tour completion, stop purpose, stop location, and stop time period.

In the Birmingham, AL study, truck movements are modeled as individual tours, which may or may not return to the starting point at the end of the day and which may make intermediate stops. In doing so, the model uses truck-mounted GPS data as model inputs and calibrators. Data consist of records containing the truck ID, start date/ time, start zone, end date/time, end zone, and travel distance (calculated from latitude/ longitude). Early data processing converts raw GPS data into truck tour records that can serve as model inputs. Then the tour's main destination zone is identified along with the number of intermediate stops, stop locations, and the tour's starting time period. Figure 2 illustrates the components of the Birmingham tour-based truck model structure.

The tour generation model develops an estimate of the aggregate number of tour origins per zone. The model requires zonal socio-economic such as employment, population, households, university enrollment, land area, zone type, truck zone, etc.

For primary destinations, the destination zones were determined using a logit choice model, with the probability of a truck going to any one zone is computed based on the utilities of each of the candidate destination zones, as shown in Equation (1)

$$
P_{i j}=\frac{\mathrm{e}^{U_{j}}}{\sum_{x} \mathrm{e}^{U_{x}}}
$$

where " $p$ " is the probability of going from zone $i$ to zone $j, ~ " x$ " is the range of candidate destination zones, and " $U$ " is a linear function of various attributes of the origin zone $i$ and destination zone $j[27]$.

The intermediate stop model addressed two tour decisions: the number of intermediate stops and the locations of those stops. The intermediate stops reflect the tripchaining nature of truck tours, which is an important characteristic of tour-based freight modeling.

The time of day model was used to assign the tour starts to one of four time periods currently used by the RPCGB in the trip-based model, namely AM peak, midday, PM peak, and night.

In the trip accumulator step, the individual truck trip table was obtained from tour records and prepared for trip assignment. Finally, the traffic assignment assigned the truck trips to the road network.

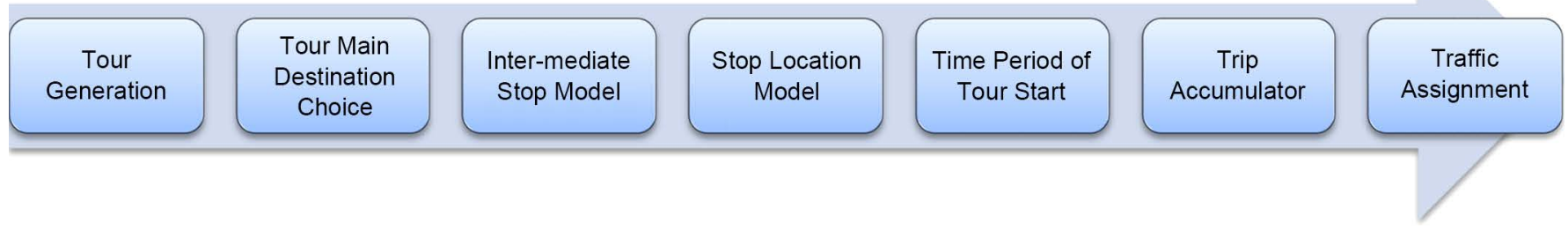

Figure 2. Tour-based model structure. 


\section{Truck GPS Data}

The principal source of data used to construct the prototype tour-based truck model was truck GPS data for the Birmingham region purchased from the American Transportation Research Institute (ATRI). The data were collected by trucks equipped with GPS units traveling through the study region. The equipment captured the truck's location, the date, and the time of day at regular intervals. The location points and times provided a record of the truck's movement that was stored on a device on board of the truck and later downloaded. Truck operators provided the data to ATRI, which removed most of the identifying information to provide anonymity and repackage the data for sale.

For this study, GPS data at the traffic analysis zone (TAZ) level were obtained for four months in 2011 namely February, May, July, and October (see Table 1). Eight sets of input files were used, each representing truck data collected over a week's time period. Data processing was necessary to remove weekend data from the database and keep only week day data. Moreover, data collected over national holidays were also omitted. It was observed that some GPS records spanned over a multi-day period. Records spanning a period other than midnight over two consecutive days were also deleted.

\section{Issues with Transfer of the Modeling Framework}

Several issues were encountered when transferring from RPCGB's current trip-based model to the prototype tour-based freight model. First, the tour-based model was developed using ATRI's 2011 truck GPS database, which was built on a 999 internal TAZ system and external stations. Although RPCGB's 2035 model was built on the same 999 TAZ system, the model was developed using 2008 socioeconomic and traffic data, meaning that the results would not be directly comparable to the tour-based model. Moreover, the RPCGB model did not include any time-of-day (TOD) component. To address these issues, the RPCGB's 2035 model was redeveloped using 2010 socioeconomic and traffic data. Moreover, a TOD model was inserted into 2035 model so that outputs could be directly compared with the tour-based model.

While the prototype tour-based model was very valuable in demonstrating the proofof-concept, it soon became obsolete due to changes that occurred in the base RPCGB

Table 1. Birmingham truck GPS data.

\begin{tabular}{cc}
\hline Birmingham Truck Data Collection Periods & Observations Obtained \\
\hline February 2011 & $1,068,591$ \\
May 2011 & $1,154,229$ \\
July 2011 & $1,109,508$ \\
October 2011 & $1,156,712$ \\
Total & $4,489,040$ \\
\hline
\end{tabular}


model that demanded the tour-based model to run with RPCGB's current year 2040 model (an update over the 2035 model). This prompted the need for additional model updates to a) expand the model in order to run on the new 1986 internal TAZs and external stations network and b) develop conversion tables to map the truck model and ATRI data to the new zone system. Since the new RPC 2040 model already includes a TOD component, this should provide a better framework to compare model outputs and test the impacts on the long range planning process.

\section{Birmingham Tour-Based Model Update}

Due to changes in boundaries between the 2000 and 2010 census data, the total number of internal and external TAZ's for the Birmingham model almost doubled increasing from 999 to 1986. Therefore, socio-economic (SE) data from census, required for the tour-based model development, were updated to the new TAZs. This is important as most data sources conform to U.S. Census Bureau geographic boundaries, such as the census blocks, block groups, or tracts, rather than TAZs.

To update the 999 zone prototype Birmingham tour-based model to the 1986 zone model, the centroid locations of the 999 old TAZs were found using ArcGIS and their coordinates were obtained and stored. The new TAZ structure was overlaid on the centroid location from the previous structure to determine which zone from the new structure matched the location from the previous structure (see Figure 3). An equivalency file between the old and new zone systems was created and utilized in order to convert the original truck origin/destination table to the one reflecting the new TAZ system. The process of assigning the new zone number to the origin/destination table for the new TAZs was performed using a routine in Excel that enabled record updating once a relationship table was developed between the original and the new zone location.

Furthermore, the new zonal boundaries were appraised by placing the model highway network on top of the TAZ coverage and verified that no zones were bisected by major roadways.

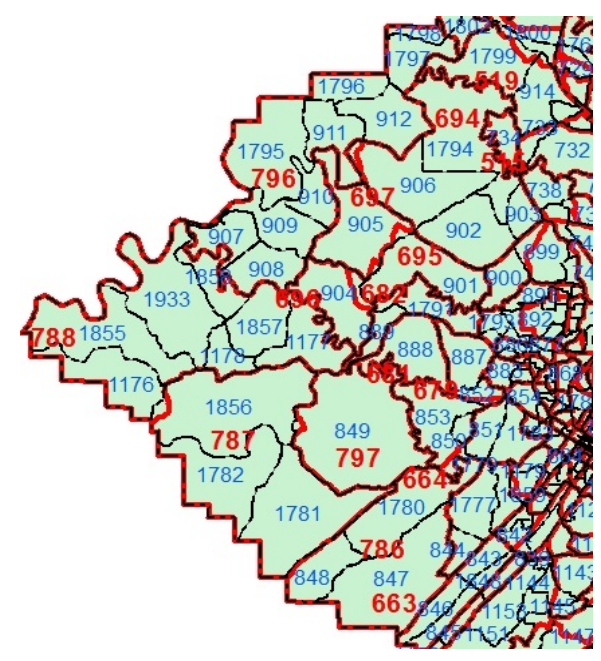

Figure 3. Old TAZ and new TAZ system overlay. 


\section{Tour-Based Model Validation}

The tour-based truck model was integrated into the RPCGB model and the final trip assignments were validated using truck counts obtained by the Alabama DOT (ALDOT). The data available on truck volumes came in the form of Annual Average Daily Traffic $(\mathrm{AADT})$ and truck percentages along ALDOT traffic count stations. The truck counts represent weekday counts in 2012. Truck counts by hour or time period were not available. Due to the heaviest truck volumes being found on the major freight Interstate corridors, the validation was performed for the roadways with the highest truck volume (54 locations). The model validation indicates a good fit between the observed and estimated link-level truck volumes (see Figure 4).

Of the many useful statistics that can be calculated for the regional-level validation, the percent root-mean square error (\%RMSE) is a better indicator of model accuracy because the square root of a variance, RMSE, can be interpreted as the standard deviation of the unexplained variance, and has the useful property of being in the same units as the response variable. The \%RMSE for updated RPCGB trip-based model and the new tour-based model were calculated using Equation (2) below [28].

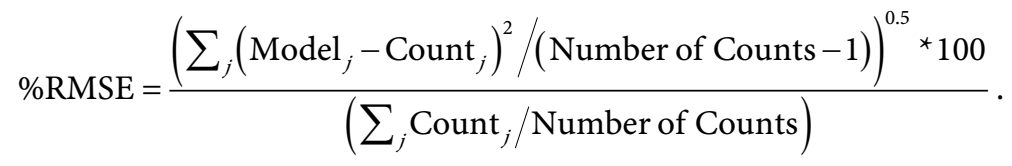

By using link-level truck volumes obtained from model outputs and traffic counts, the overall \%RMSE value of $31.8 \%$ was calculated for the updated tour-based model which is a very good value for a truck model. According to the Montana Department of Transportation, most appropriate aggregate \%RMSE is less than 30 percent [28]. An overall \%RMSE value of $100 \%$ was computed for the new RPCGB model, much lower than the value obtained for the same under the old TAZ system (204\%).

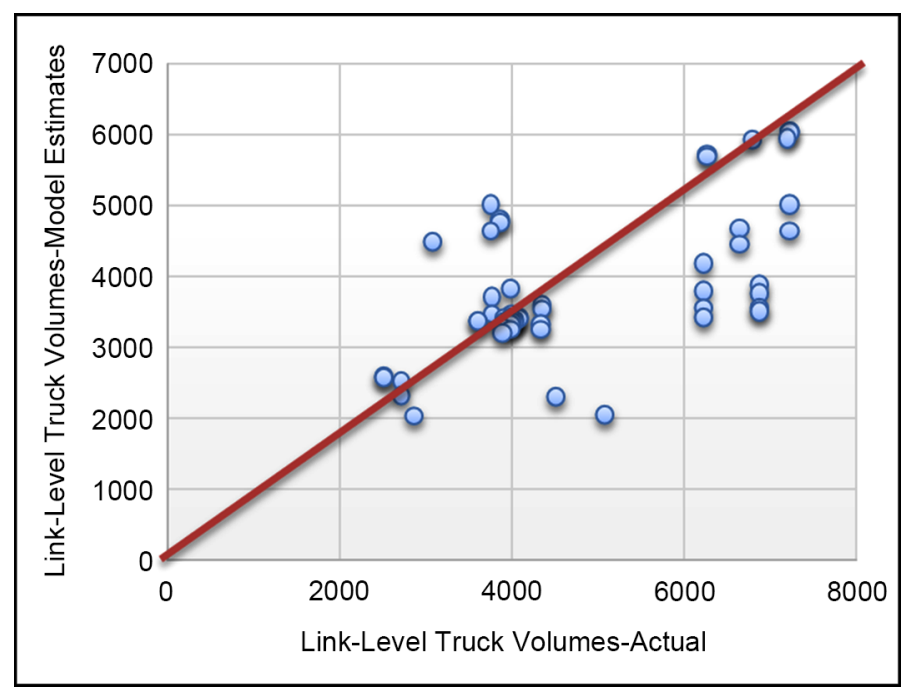

Figure 4. Model validation; observed/estimated link-level truck volumes plot. 


\section{Comparison of Models Output}

The recently updated RPCGB trip-based model and the new tour-based model were run and the results were compared across a variety of outputs. Some of the key findings are presented in the following sections.

\subsection{Truck Volume}

As shown in Figure 5 and Figure 6, the tour-based model generated higher truck volumes than the RPCGB trip-based model during the PM and NT time periods studied. This suggests that the existing trip-based model compared to tour-based model has been underestimating afternoon peak and nighttime truck traffic while it overestimated $A M$ and MD traffic. This finding could have significantly impacts to the planning process for RPCGB.

\subsection{Truck Vehicle Miles Traveled}

Vehicle-miles Traveled (VMT) refers to the number of miles vehicles travel over a given time period, and is routinely used to measure traffic on roads and to calculate important statistics including traffic fatalities, fuel efficiency and air quality.

Truck VMT were obtained from both RPCGB trip-based model and the new tourbased model and compared. The truck VMT for each model link was estimated by multiplying the truck volume by the link length. For each volume group $j$, truck VMT was calculated by summing the truck VMT of all sections of roads in that group, as formulated in Equation (3) below;

$$
\operatorname{TruckVMT}_{j}=\sum_{i=1}^{n_{j}}\left(\operatorname{Truck} V_{i j}\right)\left(L_{i j}\right)
$$

where $L_{i j}$ is the roadway length for section $i$ in volume group $j$, and $V_{i j}$ is the corresponding truck volume on that section [17]. The total value of VMT by trucks across the study area network was determined for the RPCGB's trip-based model and the new tour-based model and compared.

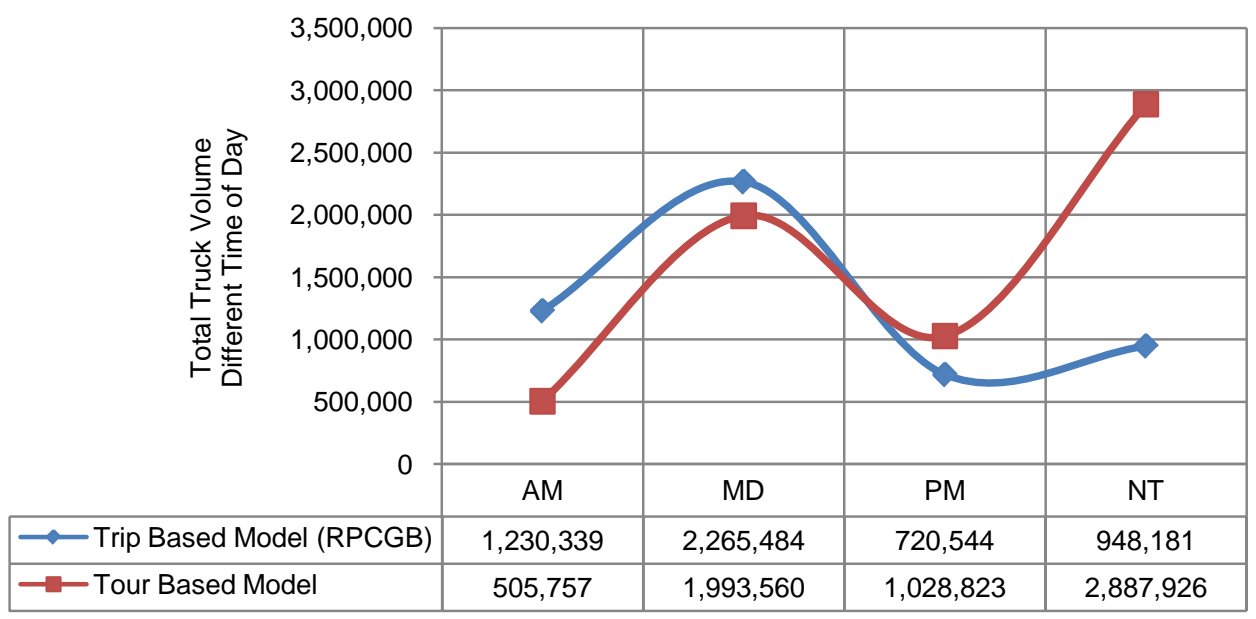

Figure 5. Truck volume in time of day trip-based vs. tour-based Birmingham model. 

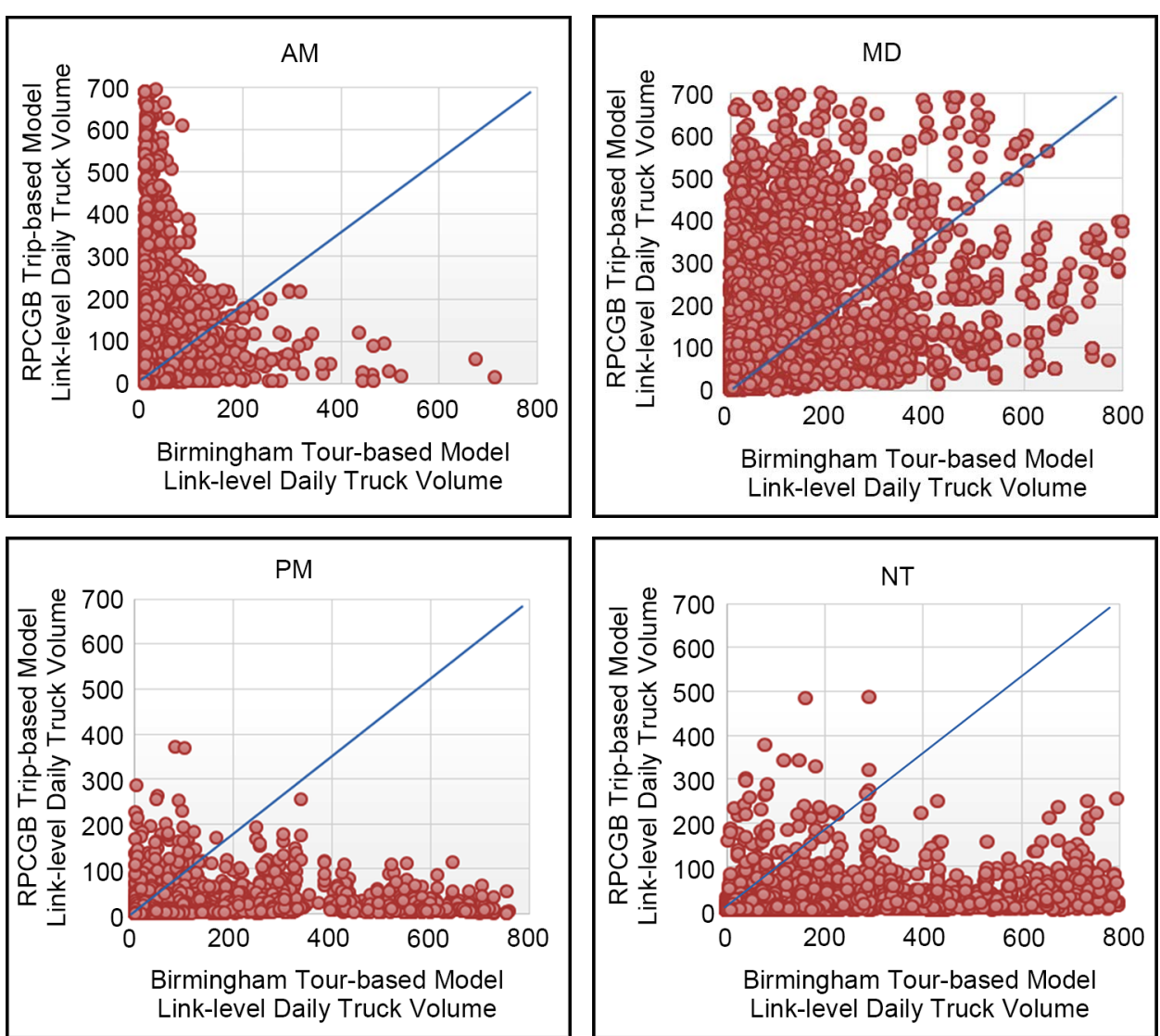

Figure 6. Link-level truck volume by time of day for the Birmingham trip-based and tour-based models.

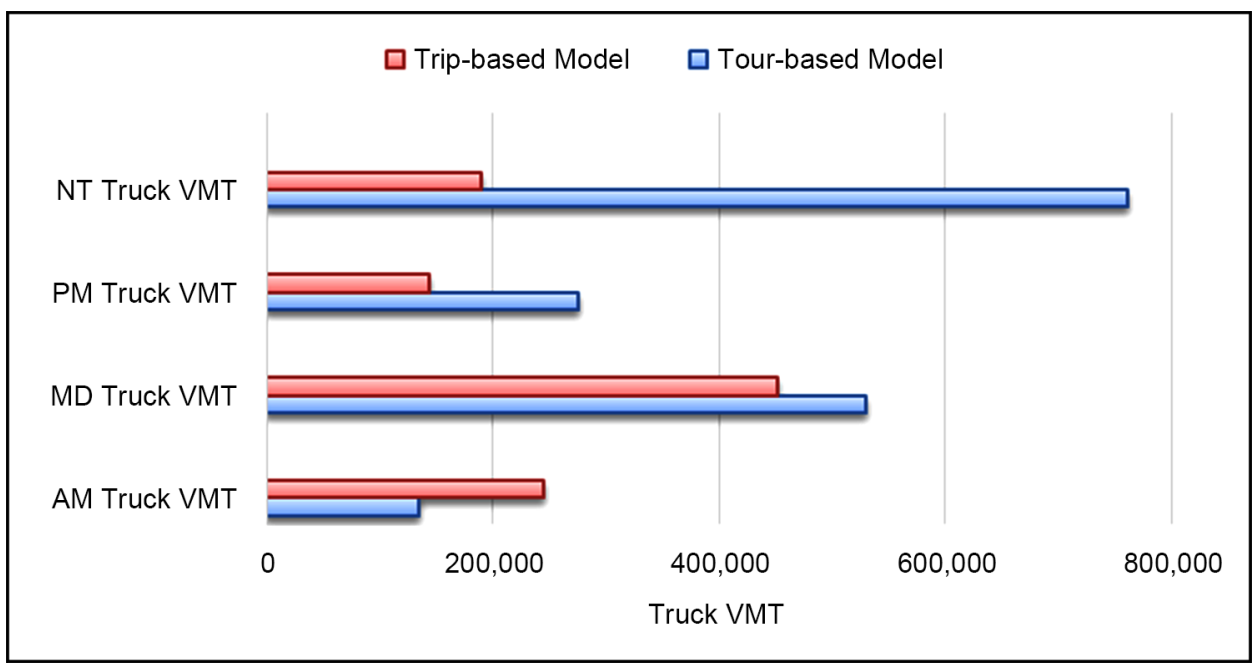

Figure 7. Truck VMT by time of day for trip-based vs. tour-based Birmingham models.

Figure 7 displays the truck VMT results by time period for both the trip-based and tour-based Birmingham models. The results illustrate that the total daily truck VMT from the tour-based model is greater than that obtained from the RPCGB's trip-based 
model for all periods, except the AM period. It is also worth noting that the NT and PM truck VMT values of the tour-based model are significantly higher than those of the trip-based model.

The findings demonstrate that the RPCGB trip-based model significantly underestimates afternoon peak and nighttime truck traffic when compared with the results from its tour-based counterpart. Such findings can have significant impacts to the regional planning process and thus require further investigation and validation.

\section{Conclusions}

The results from the Birmingham case study demonstrate a good agreement between the truck tour-based model and the field truck counts. The overall RMSE value of $31.8 \%$ obtained from the tour-based model validation process of the Birmingham model is a good value for a truck model as most truck models in the literature have RMSE values around $60 \%-80 \%$. It is also evident that modeling discrete tours is a more accurate way to represent actual truck movements that modeling zonal averages.

Moreover, when compared with the tour-based model, the performance measures obtained from the current RPCGB model show that the latter significantly underestimates truck volumes and truck VMT, particularly during the PM and NT periods. This is a key finding that can have direct application to the planning and modeling process in Birmingham region.

Although, this study is valuable because it demonstrates the feasibility of implementing a tour-based approach when modeling truck trips at the regional level, further investigation of the accuracy of new tour-based model compared to other planning models is recommended for future work.

Overall, the study is expected to provide guidance to other researchers and practitioners regarding ways to improve the accuracy of their travel demand forecasting models in the future.

\section{Acknowledgements}

The authors wish to acknowledge the expert guidance of Dr. David Lee of Georgia Institute of Technology and Mr. William G. Allen, Transportation Planning Consultant in the development of the prototype model framework. The authors extend special thanks to Dr. Michael D. Anderson and Dr. Ozge Cavusoglu for their valuable insights and support with the refinement of the updated Birmingham model and appreciation to the RPCGB personnel for their assistance with providing Birmingham truck data and facilitating model testing.

\section{References}

[1] Allen, W. (2011) Tour-Based Model for a Small Area. 11 th National Transportation Planning Applications Conference, Atlanta, GA, February 2011. http://www.williamgallen.com/STM_Presentation22sep16.pdf

[2] Ambrosini, C. and Routhier, J.-L. (2004) Objectives, Methods and Results of Surveys Car- 
ried out in the Field of Urban Freight Transport: An International Comparison. Transport Reviews, 24, 57-77. http://dx.doi.org/10.1080/0144164032000122343

[3] Beagan, D.F., Fischer, M.J. and Kuppam, A.R. (2007) Quick Response Freight Manual II. http://trid.trb.org/view.aspx?id=859168

[4] Cambridge Systematics, National Cooperative Highway Research Program, \& Transportation Officials (2008) Forecasting Statewide Freight Toolkit (Vol. 606). Transportation Research Board.

[5] Cambridge Systematics (2009) Maryland Statewide Freight Plan. http://www.mdot.maryland.gov/newMDOT/Freight/Documents/Freight_Plan_Final.pdf

[6] Cambridge Systematics (2010) Freight-Demand Modeling to Support Public-Sector Decision Making. Transportation Research Board, No. NCFRP 8. http://onlinepubs.trb.org/onlinepubs/ncfrp/ncfrp_rpt_008.pdf

[7] Chow, J.Y.J., Yang, C.H. and Regan, A.C. (2010) State-of-the Art of Freight Forecast Modeling: Lessons Learned and the Road Ahead. Transportation, 37, 1011-1030. http://dx.doi.org/10.1007/s11116-010-9281-1

[8] De Jong, G., Gunn, H. and Walker, W. (2004) National and International Freight Transport Models: An Overview and Ideas for Future Development. Transport Reviews, 24, 103-124. http://dx.doi.org/10.1080/0144164032000080494

[9] Fischer, M., Outwater, M., Cheng, L., Ahanotu, D. and Calix, R. (2005) Innovative Framework for Modeling Freight Transportation in Los Angeles County, California. Transportation Research Record: Journal of the Transportation Research Board, 1906, 105-112. http://dx.doi.org/10.3141/1906-13

[10] American Transportation Research Institute (2012) Freight Performance Measures. http://atri-online.org/2012/02/28/freight-performance-measures/

[11] Bassok, A., McCormack, E.D., Outwater, M.L. and Ta, C. (2011) Use of Truck GPS Data for Freight Forecasting. Transportation Research Board 90th Annual Meeting. http://trid.trb.org/view.aspx?id=1092809

[12] Du, J. and Aultman-Hall, L. (2007) Increasing the Accuracy of Trip Rate Information from Passive Multi-Day GPS Travel Datasets: Automatic Trip End Identification Issues. Transportation Research Part A: Policy and Practice, 41, 220-232. http://dx.doi.org/10.1016/j.tra.2006.05.001

[13] Greaves, S.P. and Figliozzi, M.A. (2008) Commercial Vehicle Tour Data Collection Using Passive GPS Technology: Issues and Potential Applications. Institute of Transport and Logistics Studies.

[14] Kuppam, A., Lemp, J., Beagan, D., Livshits, V., Vallabhaneni, L. and Nippani, S. (2014) Development of a Tour-Based Truck Travel Demand Model using Truck GPS Data. 93rd Annual Meeting of Transportation Research Board, Washington DC, January 2014. 4-27. http://docs.trb.org/prp/14-4293.pdf

[15] Samimi, A., Mohammadian, A. and Kawamura, K. (2010) Behavioral Freight Movement Modeling. The 12 th International Conference on Travel Behavior Research, Jaipur, India, December 2009, 1-23.

https://iatbr2009.asu.edu/ocs/custom/resource/W4_R1_Behavioral\%20Freight\%20Moveme nt\%20Modeling.pdf

[16] Doustmohammadi, E., Sisiopiku, V., Anderson, M., Doustmohammadi, M. and Sullivan, A. (2016) Comparison of Freight Demand Forecasting Models. International Journal of Traffic and Transportation Engineering, 5, 19-26.

[17] Federal Highway Administration (2007) Quick Response Freight Manual I and II. Freight 
Management and Operations.

[18] Figliozzi, M.A., Kingdon, L. and Wilkitzki, A. (2007) Analysis of Freight Tours in a Congested Urban Area Using Disaggregated Data: Characteristics and Data Collection Challenges. Analysis, 12, 1-18.

http://pdxscholar.library.pdx.edu/cgi/viewcontent.cgi?article $=1068 \&$ context $=$ cengin_fac

[19] Gliebe, J., Smith, C. and Shabani, K. (2013) Tour-Based and Supply Chain Modeling for Freight in Chicago.

http://www.cmap.illinois.gov/documents/10180/98867/20130919_PeerExch_Gliebe_CMAP ACE_FreightModel_PanelMeetingV04.pdf/bedc1a2c-c8a3-4eba-90ad-95edae1a34eb

[20] Hunt, J.D. and Stefan, K.J. (2007) Tour-Based Microsimulation of Urban Commercial Movements. Transportation Research Part B: Methodological, 41, 981-1013. http://dx.doi.org/10.1016/j.trb.2007.04.009

[21] Kim, H., Park, D., Kim, C. and Kim, Y. (2011) A Tour-Based Approach to Destination Choice Modeling Incorporating Agglomeration and Competition Effects. Proceedings of the Eastern Asia Society for Transportation Studies, Vol. 8. http://www.dasan93.co.kr/upload/resear/resear1_12924153145.pdf

[22] Knudson, B., Hunt, J., Weidner, T., Bettinard, A. and Wardell, E. (2011) Effective Modeling Analysis: A Case Study Using the Oregon Statewide Integrated Model for the Oregon Freight Plan. 2011 TRB Transportation Planning Applications Conference. http://www.oregon.gov/ODOT/TD/TP/docs/Statewide/EffModeling.pdf

[23] Outwater, M., Smith, C., Wies, K., Yoder, S., Sana, B. and Chen, J. (2013) Tour Based and Supply Chain Modeling for Freight: Integrated Model Demonstration in Chicago. Transportation Letters. The International Journal of Transportation Research, 5, 55-66. http://dx.doi.org/10.1179/1942786713Z.0000000009

[24] Ruan, M., Lin, J.J. and Kawamura, K. (2012) Modeling Urban Commercial Vehicle Daily Tour Chaining. Transportation Research Part E: Logistics and Transportation Review, 48, 1169-1184. http://dx.doi.org/10.1016/j.tre.2012.06.003

[25] U.S. Census Bureau \& BTS (2010) Commodity Flow Survey. Bureau of Transportation Statistics. http://www.bts.gov/publications/commodity_flow_survey/

[26] Wang, Q. and Holguin-Veras, J. (2010) A Tour-Based Urban Freight Transportation Model Based on Entropy Maximization. SHRP2 Innovations in Freight Demand Modeling and Data Symposium, Washington DC, 15 September 2010, 1-5.

[27] Spear, B.D. (1977) Applications of New Travel Demand Forecasting Techniques to Transportation Planning, USDOT, Office of Highway Planning.

[28] Wegman, F. and Jerry, E. (2012) Minimum Travel Demand Model Calibration and Validation Guidelines for State of Tennessee. 
Submit or recommend next manuscript to SCIRP and we will provide best service for you:

Accepting pre-submission inquiries through Email, Facebook, LinkedIn, Twitter, etc. A wide selection of journals (inclusive of 9 subjects, more than 200 journals)

Providing 24-hour high-quality service

User-friendly online submission system

Fair and swift peer-review system

Efficient typesetting and proofreading procedure

Display of the result of downloads and visits, as well as the number of cited articles

Maximum dissemination of your research work

Submit your manuscript at: http://papersubmission.scirp.org/

Or contact jtts@scirp.org 